\title{
ERRATUM
}

Sandra E. Kleiman · Leah Yogev $\cdot$ Ron Hauser

Amnon Botchan · Batia Bar-Shira Maymon

Letizia Schreiber · Gedalia Paz $\cdot$ Haim Yavetz

\section{Members of the CDY family have different expression patterns: CDY1 transcripts have the best correlation with complete spermatogenesis}

Published online: 12 December 2003

(C) Springer-Verlag 2003

\section{Hum Genet (2003) 113:486-492}

In Fig. 2 of this article the numbers above the columns were given incorrectly. The correct figure is reproduced here.

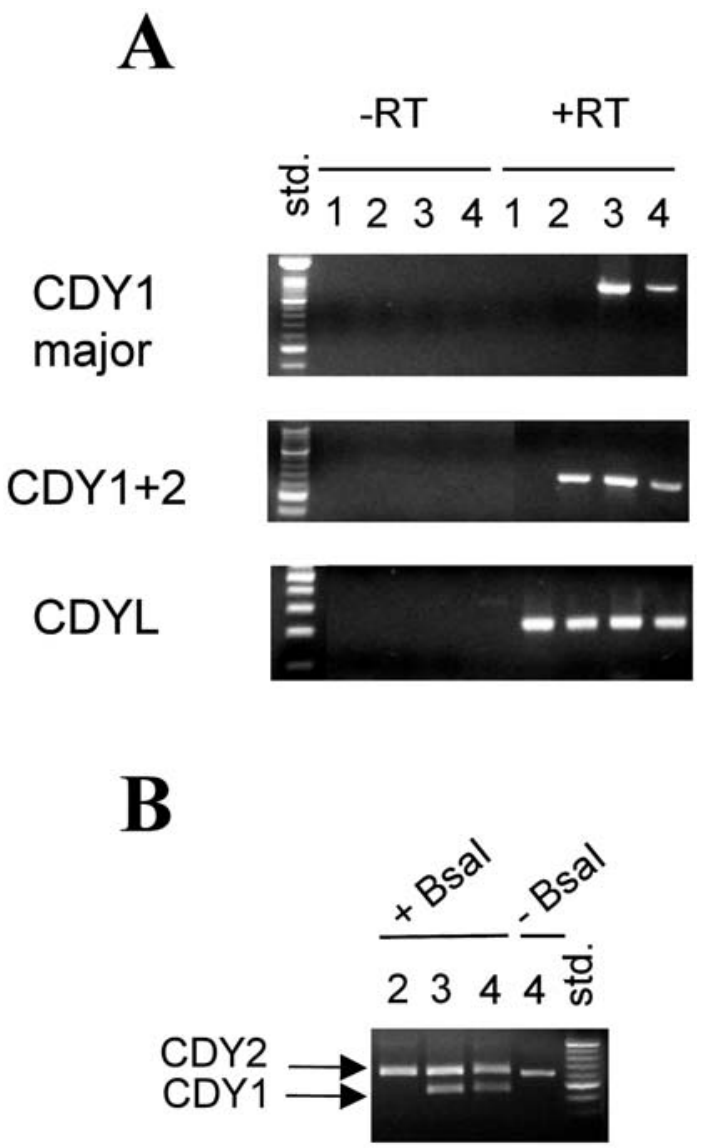

The online version of the original article can be found at http://dx.doi.org/10.1007/s00439-003-0990-9

S. E. Kleiman $(\bowtie) \cdot$ L. Yogev $\cdot$ R. Hauser $\cdot$ A. Botchan $\cdot$ G. Paz H. Yavetz

Institute for the Study of Fertility, Lis Maternity Hospital,

Tel Aviv Sourasky Medical Center,

Sackler Faculty of Medicine, Tel Aviv University,

6 Weizman Street, 64239 Tel Aviv, Israel

Tel.: +972-3-6925748, Fax: +972-3-6925696,

e-mail: ser@tasmc.health.gov.il

B. Bar-Shira Maymon · L. Schreiber

Institute of Pathology, Tel Aviv Sourasky Medical Center,

Sackler Faculty of Medicine, Tel Aviv University,

Tel Aviv, Israel

Fig. 2A, B Testicular expression of CDY1 major, CDY2, and $C D Y L$. A RT-PCR with $C D Y 1$ major, $C D Y 1+2$, and $C D Y L$ sets of primers. B Detection of $C D Y 1$ and $C D Y 2$ by restriction site assay with (+) and without (-) the BsaI enzyme. Lane 1 Sertoli cell only, lane 2 spermatocyte maturation arrest, lane 3 hypospermatogenesis, lane 4 normal spermatogenesis (std 100 bp ladder standard) 